\title{
Ferreira da Silva Homem de Ciência e de Pensamento (1853-1923)
}

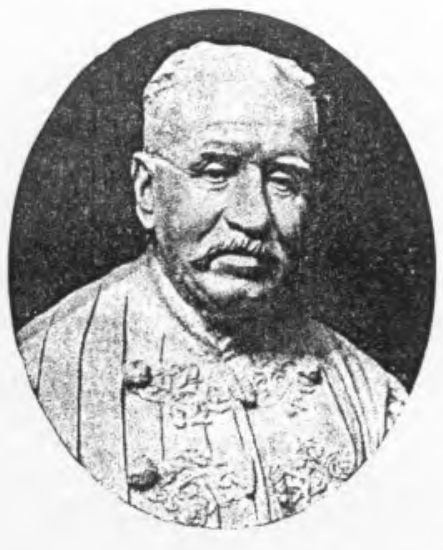

O nome de Ferreira da Silva merece, inegavelmente, que o apontem aos que o desconhecem e que $o$ recordem aos que já o esqueceram. Ferreira da Silva foi mestre distintíssimo, cientista de grande mérito e caracter nobilíssimo. Qualquer destas três afirmações poderia ser demonstrada com largueza.

Ferreira da Silva foi um dos raros portugueses cujos estudos de Química passaram além das nossas fronteiras, merecendo os elogios de alguns dos mais respeitados investigadores estrangeiros do seu tempo. São extremamente significativas as palavras consagradas à sua memória quando, em 1923, a notícia do seu falecimento chegou aos vários organismos científicos europeus. O professor Guillaume, director do Bureau International de Poids et Mesures, de Sèvres, escreveu, a propósito da triste notícia: "Il m'avait été donné de rencontrer pour la première fois le Professeur Ferreira da Silva à des réunions pour la création d'un Institut International des méthodes d'analyse et j'avais été frappé, comme cachun, de son intelligence claire et vive, de sa netteté dans l'exposition et de sa puissance de réalisation, en même temps que son immense savoir..."... «il laisse le précieux souvenir du bien qu'il a fait par son enseignement, par la fondation de la Société Chimique Portugaise, sou- tout par ses travaux personnels qui assurent à sa mémoire la reconnaissance des générations futures". Sabatier, professor da Universidade de Toulouse e nome familiar aos estudiosos da Química, escrevia, em carta dirigida aos filhos de Ferreira da Silva: «J'ai appris la mort de votre regretté père dont $\mathrm{j}$ 'avais depuis longtemps apprécié la haute valeur scientifique. Son souvenir demeurera dans la domaine chimique où il a apporté un contingent de travaux".

Não the faltaram, enquanto vivo, as homenagens das agremiações estrangeiras. Pertenceu à "Sociedad Española de Fisica y Quimican, à «Real Accademia de Ciencias exactas, físicas e naturales", à "Société Chimique de France", à "Société de Pharmacie de Paris", à "Association des chimistes de Sucrerie et Distillerie de France et des colonies", à "Société française de Physique", à "Société scientifique d'hygiène alimentaire et d'alimentation rationelle de l'homme", "Comission internationale pour la repression des fraudes", à "Comission permanente de l'alimentation humaine", à "Association internationale pour les progrès de l'Hygiène", à "Société chimique de Belgique", à "Società chimica italiana", à "Pontificia Accademia Romana dei Nuovi Lincei», à "Deutschen Chemischen Gesellschaft", à "American Chemical Society".

Os portugueses, porém, são muito exigentes com os seus homens de valor. Dir-se-ia que lhes é mais fácil tecer elogios a quem menos os merece. Perante os reais valores, hesitam, regateiam, aviltam e espesinham. Somos poucos e não nos unimos; somos fracos e não nos auxiliamos; somos pequenos e não nos engrandecemos. Ferreira da Silva, a quem o Governo francês nomeou cavaleiro da Legião de Honra por decreto de 1908, foi a enterrar, seguido e chorado por amigos sinceros, sem qualquer repre- sentação oficial do país que tanto enobreceu.

Como poucos - e exactamente por se ter evidenciado como pou$\cos$ - sentiu a ferroada dos invejosos, a insídia dos maldizentes, a raivazinha dos medíocres. "Quando se iniciou no Porto - escreveu Ferreira da Silva - a fiscalização sanitária dos géneros alimentícios, depois da descoberta de fraudes nas farinhas... tive de descer à estacada, no intuito de orientar esse serviço, que eu pensava estar mal encaminhado. Concitei contra mim imediatamente as más vontades, e até ódios, da medicina sanitária e não sanitária; fizeram-se-me as maiores injustiças, de que quase eu só tive de defenderme; e até os tribunais me olharam de soslaion.

A obra científica de Ferreira da Silva não é própria, pelos assuntos que versa, para impressionar o grande público como sucede, por exemplo, com certas aquisições espectaculares da técnica moderna. É uma obra de investigação aturada, minuciosa, paciente, que assegurou e alargou os conhecimentos no campo da Toxicologia, da Química aplicada à Alimentação, à Higiene, à Hidrologia, à Farmácia, à Indústria, ao Comércio e à Agricultura. São particularmente valiosos os seus estudos sobre os alcalóides, como o provam os trabalhos publicados pela Academia de Ciências de Paris: "Sur une nouvelle reaction de la cocainne" (1890), "Sur l'emploi du sulfosélénite d'ammoniaque pour caracteriser les alcaloïdes" (1890) e "Sur une nouvelle reaction de l'éserine et une matière verte derivée du même alcaloïde" (1892). São igualmente valiosos os seus escritos sobre a constituição dos derivados metálicos do acetileno, atestados pelos seguintes trabalhos: "Sur la constitution des carbonyles métalliques" (1896) e "Sur la réfraction atomique des metaux dans les carbonyles métalliques et les formules de constitution 
de ces derivés" (1900), ambos publicados no Bulletin de la Société Chimique de Paris, e "Sur la constitution des dérivés métaliques de l'acétylène, et sur l'acétylène comme lien entre la chimie minérale et la chimie organique" (1913) publicado em Roma nas memórias da Academia dei Nuovi Lincei.

De grande celebridade no seu tempo foi a polémica, longa, acesa e áspera sustentada por Ferreira da Silva contra adversários nacionais e estrangeiros, sobre a pretendida salicilagem dos vinhos portugueses. A questão que deu origem a centenas de páginas (a colectânea de documentos, publicada oficialmente, ocupa quase 600 páginas) deu ao nome do eminente químico português merecida fama e respeitado prestígio. O seu trabalho "Sur une cause d'erreur dans la recherche de l'acide salicylique dans les vins portugais", primeiramente publicado nos "Comptes Rendus" da Academia de Paris, foi reproduzido em várias revistas científicas de primeira plana.

Recordemos, em rápidas linhas, o que foi a questão da salicilagem.

Nos fins do século passado (1884) era permitido adicionar aos nossos vinhos uma pequena dose de ácido salicílico ( 10 a $15 \mathrm{~g}$ por hectolitro) para efeitos de conservação. Em particular, o vinho exportado beneficiava, desse modo, duma garantia maior de inalterabilidade. Sucedeu, porém, ter-se atribuído ao ácido salicílico certas qualidades prejudiciais ao nosso organismo, o que motivou, da parte dos países importadores, a mais rigorosa fiscalização alfandegária. Os vinhos eram analisados à chegada a esses países e recusados se a análise indicava qualquer sinal da presença do referido ácido.

A questão da salicilagem teve origem nos vinhos portugueses enviados para o Brasil. Embora os nossos exportadores acatassem a ordem que proibia a adição de ácido salicílico aos seus vinhos, os peritos brasileiros, encarregados da análise desses vinhos à chegada dos nossos navios, afirmavam que o ácido fora adicionado e acusavam a nossa exportação de fraudulenta. Como a afirmação fosse insistente e, pelo menos aparentemente, fundamentada, o Brasil fechou as suas portas comerciais à entrada dos nossos vinhos.

A grave situação criada pelo encerramento dum mercado de tão grande importância para a nossa economia, traduziu-se em protestos clamorosos e indignados dos exportadores portugueses que afirmavam não adicionarem, aos seus vinhos, a mínima parcela de ácido salicílico.

Ferreira da Silva, encarregado de apreciar a questão no aspecto científico que era do seu domínio, analisou cuidadosamente amostras de vinhos de várias procedências, iguais aos exportados, e manteve a afirmativa de que não continham ácido salicílico. Entretanto, não se podia pôr em dúvida a afirmação categórica dos analistas brasileiros.

Os processos empregados para reconhecer a presença do ácido salicílico baseiam-se na sua reacção com o tricloreto de ferro caracterizada pelo aparecimento dum tom violáceo.

Começa-se por agitar o vinho com éter, o qual dissolverá o ácido salicílico que estiver presente. A solução etérea que, devido à sua fraca densidade, se separa da massa líquida restante, é decantada e evaporada. O resíduo, ao ser tratado pela solução de tricloreto de ferro, adquirirá então o tom violáceo.

Fundamentados nesta mesma propriedade, usavam-se dois processos que apenas diferiam em certos pormenores técnicos: o processo francês e o processo alemão. Ferreira da Silva, que empregava o processo alemão, teve conhecimento de que os brasileiros empregavam o processo francês. Ensaiou ambos e reconheceu que, para o mesmo vinho, (ao qual, de certeza, não fora adicionado ácido salicílico), o processo francês dava origem à reacção característica da presença do ácido (o tom violáceo) enquanto o alemão nada acusava! Surgia assim a primeira luz para o esclarecimento da questão.
O problema científico punha-se então deste modo: existe no vinho, que não sofreu qualquer adição, uma substãncia desconhecida que tem a mesma propriedade que o ácido salicílico de adquirir a tonalidade violácea quando reage com a solução de tricloreto de ferro. A presença dessa substância desconhecida só é revelada pelo processo francês, mais sensível do que o alemão, talvez por aquele exigir maior quantidade de vinho nas manipulações da sua análise.

Foi então que Ferreira da Silva escreveu o seu trabalho "Sur une cause d'erreur dans la recherche de l'acide salicylique dans les vins portugais", que o eminente químico Berthelot apresentou à Academia de Ciências de Paris (13 de Agosto de 1900). O alarme provocado por essa manipulação foi sensacional por levantar dúvidas, então insuspeitadas, àcerca dos referidos métodos de análise. Pellet, um dos autores do processo francês de investigação do ácido salicílico nos vinhos (o processo tem a designação de Pellet-Grobert-Baudrimont) veio imediatamente, bem depressa se sentiu na necessidade de homenagear o químico português, apoiando-o sem reservas. "Ferreira da Silva - escreveu Pellet nos "Annales de Chimie analytiquen, em 15 de Novembro de 1900 - a donc rendu un réel service en signalant cette cause d'erreur, tant au point de vue scientifique qu'au point de vue commercial».

A questão levantada por Ferreira da Silva interessou grande número de químicos na procura de qual seria a tal substância de propriedades semelhantes ao ácido salicílico que existia no vinho e servia de fundamento à proibição da entrada dos nossos vinhos no Brasil. O professor alemão Mastbaum, que viveu mais de cinquenta anos em Portugal, o químico Pellet, em França, e muitos outros, dirigiram aturadamente as suas investigações sobre a misteriosa substância e chegaram à conclusão inesperada de que se tra tava... do próprio ácido salicílico. Isto é, muitos vinhos contêm, por natureza, certa percentagem, muito fraca, de ácido salicílico. O processo 
de análise de Pellet, mais sensível, distingue a presença dessa fraca percentagem; o processo alemão, menos sensível, não a distingue. Eis a chave do mistério.

A questão da salicilagem arrastou-se durante dois anos (19001902), tanto foi o tempo necessário para vencer a atitude dos analistas brasileiros que não se dispunham a aceitar as razões de Ferreira da Silva.

Entre nós, a actuação do químico português, em vez de ser alvo de unânime aplauso, foi motivo das mais insisdiosas maledicências. A má língua nacional não teve pejo em acusar Ferreira da Silva de pretender encobrir, com a sua autoridade (aliás posta em dúvida pelos detractores), as fraudes, consideradas premeditadas, dos exportadores de vinhos. Estes, adicionariam criminosamente o ácido salicílico; Ferreira da Silva, com conhecimento da fraude, pretenderia demonstrar a inocência dos traficantes.

Finalmente, dois anos depois de iniciada a questão, o mercado brasileiro foi novamente aberto aos nossos vinhos.

A aridez dos assuntos tratados nas comunicações científicas a que nos temos referido, a estreiteza do âmbito da elevada especialização que revelam, poderiam fazer pensar que os interesses de Ferreira da Silva se confinavam às paredes do seu laboratório e das suas salas de aula. Não era assim. Espírito aberto e lúcido, caminhava, ele próprio, ao encontro dos grandes problemas, meditando-os, analisando-os e lutando pelas conviç̧ões adquiridas, com tanto ardor como pela sua ciência de eleição. Percorrendo a longa lista (mais de trezentos títulos) dos seus trabalhos impressos, encontram-se, ao lado das preocupações científicas, insistentes preocupações filosóficas. São dignos de ser recordados alguns dos seus trabalhos neste domínio, como, por exemplo, "A importância e a dignidade da sciencia" ou "O ideal religioso e a cultura scientifica”.

Ferreira da Silva, enquanto consumia a existência na investigação minuciosa dos fenómenos quí- micos, debruçado sobre os seus cadinhos e sobre as suas retortas, não esquecia o papel social que ele próprio estava desempenhando, pelo facto de ser cultor de uma ciência. Compreendia claramente que a ambição do cientista não pode caber nas dimensões dum cadinho.

São de Ferreira da Silva estas serenas e esperançosas palavras: "Se a sciencia não tem pretensões (nem as pode ter) a esclarecer-nos sobre a natureza íntima das coisas, nem sobre as causas primeiras, mas se limita ao estudo restricto e positivo dos factos e às leis dos fenómenos, e estes, como já dissemos, podem ser verificados em toda a parte, não há dúvida que é a única disciplina capaz de crear a unanimidade entre os homens. Assim a ciência constitui um princípio de concórdia entre eles". "A ciência, por estes motivos, exerce uma aç̧ão de conciliação, de confraternidade e de solidariedade universais". "A humanidade conduzida pela ciência para a região serena da paz, eis o que muitos hoje poderão ter como utopia ou sonho, mas que poderá ser um dia realidade».

Mais algumas frases que são verdades de ontem e de hoje: "Não só a ciência é eminentemente própria para dar ao espírito a seriedade, a firmeza e a clareza de convicções que o tornam superior às sugestões da vaidade e do interesse pessoal, o que já é uma concepção do dever, como também é uma escola de modéstia e benevolência". "O facto científico rigorosamente observado a todos obriga, porque todos o podem verificar; a lei natural, correlação necessária entre os fenómenos, a todos se impõe, pelo mesmo motivo; não há declamações oratórias, dissertações literárias, ou discussões escolásticas, que os possam modificar, ou opôr-se aos progressos que dele dimanam".

Não deixaria de ter interesse um estudo comparativo entre as mentalidades de Ferreira da Silva e de Berthelot, de quem foi admirador estreme. Salvaguardadas as devidas proporções entre as contribuições científicas de cada um deles para o progresso dos homens, encontramos, entre ambos, certo paralelismo de atitudes: o mesmo amor da Ciência, a mesma esperança no seu papel civilizador, a mesma rectidão de processos, o mesmo entusiasmo na luta a favor dos progressos do ensino, a mesma ansiedade em rever constantemente a posição moral do Homem dentro do teatro, sempre renovado, da Ciência. Enquanto Berthelot despia a sua bata de químico para escrever a "Science et Philosophie", a "Science et Morale" ou a "Science et Libre Pensée", Ferreira da Silva reunia as suas palestras doutrinárias em "Sciencia e Crenças».

Todavia, Ferreira da Silva e Berthelot doutrinavam em campos opostos que só tinham de comum a honestidade dos processos. Berthelot era inimigo declarado da Igreja. A felicidade dos homens só poderia ser alcançada por via da Ciência. Só nesta encontrava "a força moral sobre que alicerçar a dignidade da personalidade humana". As únicas bases da Moral seriam as que a Ciência lhe fornecesse. Para Ferreira da Silva, que via na Religião a origem da única força moral capaz de amparar o Homem, os conceitos de Berthelot arrepiavam, como nefandas, insuportáveis blasfémias. Contudo, tão elevada era a independência do seu carácter, tão compreensivo o seu espírito, que năo se encontra uma só palavra áspera nas várias páginas que escreveu sobre a vida e a obra de Berthelot, páginas essas que, na opinião de Jungfleisch, sucessor da cadeira de Berthelot, no Colégio de França, foram das mais belas que em todo o mundo se escreveram a propósito da morte do grande químico francês. Apesar da profundíssima incompatibilidade que os separava no campo ideológico, Ferreira da Silva escrevia acerca de Berthelot: "O seu carácter estava a par do seu talento; a sua vida pode, por mais de um motivo, tomar-se como exemplo e lição".

Só os homens excepcionalmente dotados conseguem apreciar os inimigos da sua ideologia com semelhante isenção.

Rómulo de Carvalho (1953) 